\title{
Delimiting the boundaries of a Mountain Natural Heritage Site through multi-objective modelling
}

\author{
Hui Shi, Zhaoping Yang, Tiange Shi \& Fang Han
}

Keywords: Boundary-making, multi-objective programming, game theory, land use / land cover types, heritage sites

\section{Abstract}

Defining the boundaries of natural heritage sites is critical to the protection, management and conservation of natural resources. This paper develops a multiobjective programming model based on game theory. It considers the economic and ecological benefits of various land use/land cover types, as determined by the local government and academic stakeholders' expectations. A range of boundaries is identified by the Nash equilibrium, satisfying all players' interests. Combining this with landscape types and considering geographic characteristics obtained from field investigations, we identify a final boundary for the Tomur buffer region in China's Xinjiang Tianshan World Heritage Site. This novel process greatly improves our ability to shape optimal boundaries in environmental and economic terms. Future work should aim to consider widely the value orientations of various stakeholders, combining these with the cultural values and spatial properties of land use/land cover types to obtain more socially acceptable boundaries.
Profile

Protected area

Xinjiang Tianshan World Heritage

Site

Mountain range

Tianshan

Country

China

\section{Introduction}

The world's natural heritage, formed through the earth's slow evolutionary processes, has irreplaceable scientific and aesthetic value. Establishing protected areas, such as national parks and UNESCO (United Nations Educational, Scientific and Cultural Organization) heritage sites, can effectively safeguard the world's most important ecological systems, rare and endangered species, and the unique natural environments of ruins and landscapes (Han et al. 2011; Hazen 2008). Natural heritage sites share the characteristics of being indisputable, diverse and unique. In the Operational Guidelines for the Implementation of the World Heritage Community, a boundary must be defined for such sites before a heritage declaration can be made (Gullino \& Larcher 2013). Boundaries are essential for protecting the integrity and authenticity of these areas and can prevent the core value of protected areas from being degraded by human activities (Hazen 2008; Ryan et al. 2011). Boundaries also enable unprotected areas to develop economic activities that can improve local residents' lives. Research on heritage boundary delimitation is therefore becoming increasingly valued within the academic community (Gillespie 2013). Scholars have realized that boundary-making is central to the protection of heritage sites (Fox 2002).

Boundary-making, ostensibly the process of drawing a line on a map, is realized through the social acknowledgement and acceptance of this demarcation (Ford 1999). The accepted line thus must be based on relevant geographic characteristics, landscape types, land use / land cover types, community viewpoints, local customs and other social and ecological factors
(Allendorf 2007; Wimmer 2009). Pierce (2005) and Orsi (2013) found that considering local land-use norms and practices is important for setting appropriate boundaries for resource management and conservation plans. Rao et al. (2003) and Gillespie (2013) found that World Heritage zone boundaries must take into consideration local people's knowledge, the site's aptitude and its distinctive geographic features in order to facilitate site management. Spang (2012) studied the engagement process and decision-making by stakeholders to coordinate heritage conservation of natural heritage systems.

The designation of areas as mountain natural heritage site (MNHs) is based on geological and topographical features of mountainous areas, corresponding to at least one standard of the UNESCO World Heritage Assessment Criteria vii-x (Thorsell 2003; Han 2011). On the basis of the concept of a mountain, assessments of MNHs pay considerable attention to the natural form (altitude and elevation) and scale (area) of the given mountain area. The process of delimiting the boundaries of a mountain natural heritage area is somewhat more complex than that of other non-mountainous heritage sites. First, MNHs share typical mountain characteristics, including geological relics, landforms and vertical natural zones. The process of boundary-making must thus take into account the earth's historical evolution, geomorphic change, ecological succession, the integrity of biodiversity, outstanding landscape resources and other information specific to the particular geographic environment. Second, some MNHs have rich underground mineral resources, which play an important role in local economic development. Thus, MNHs often involve contradictions between ecological protection and 
economic development. As such, the process of delimiting boundaries must closely consider stakeholders, especially local residents' demands. Third, MNHs' ecosystems contain diverse vertical zones as the elevation changes. Shifts in land use / land cover types are not necessarily consistent with the natural topographic features. Consequently the boundary-making process must consider natural landscape features (such as altitude, ridges, rivers, slope, aspect and contour lines) and the distribution of landscape types to determine a reasonable heritage boundary.

Mountainous areas thus offer an interesting case study for setting the boundaries of protected areas, a process which is not at all straightforward. To create lawful and approved boundaries, planners must also consider the demands of stakeholders, cultural norms and social practices. Various stakeholders are involved in decisions pertaining to the definition of a protected area's boundary, including researchers, central and local government actors, local communities and private organizations (Pomeroy \& Douvere 2008; Spang et al. 2012; Wei 2007). In most developed countries, local communities are the main driving force for heritage declaration and in delimiting the protected area favour the principle the bigger the better (Jimura 2011). In China, local residents of heritage sites often lack an understanding of what heritage entails. As such, the process of boundary delimitation is begun by Chinese experts, who set a basic plan for the heritage site; then relevant government departments and foreign experts review the rationality of the proposed boundary. Finally, by combining these suggestions with field surveys and operational guidelines for boundary specification, the boundaries of the nominated region and its buffer areas are confirmed (Chen 2005; Zhang 2008; Gillespie 2013).

Experts and local government actors thus play important roles in the boundary-making process under China's top-down management system. Each group is concerned with its specific interests in heritage boundary determination. Experts have mainly prioritized protecting the integrity and authenticity of the heritage value, e.g. by protecting the ecological environment, biodiversity and environmental services (Su \& Li 2012). Local government, in contrast, is considered the main market player, prioritizing its own self-interest and inclined to safeguard the region's economic development within the growth of the larger market economy (Wang \& Xu 2014). Therefore, while experts aim to protect heritage values and the environment, local government actors hope to set a reasonable boundary that can satisfy the development needs of local residents (Zhao 2008). These groups' different concerns can give rise to a clear divergence on boundary delimitation. Coordinating the views of stakeholders while fully considering the tension between heritage conservation and local development from a spatial viewpoint is the key to boundary-making.
The process of boundary-making can be viewed as stakeholders playing a strategic game to define the site's spatial scope; it can thus be examined via game theory. Game theory considers optimal decision-making under the constraints of conflicting interests through rigorous mathematical models (Binmore 2010; Zhang \& Li 2008; Nash 1950; Shapley 1953). In their applications of game theory, scholars have examined the goals of different participants in the decision-making process to determine optimal solutions to social problems, such as compensation for water pollution, relationships between plants and animals within the food chain, and management problems involved with wildlife conservation (Guthery \& Shaw 2013; Lee 2012; Moss 2010). In the field of heritage research, game theory has been used to analyse and explain the relationships, interests and choices of different stakeholders in the heritage conservation process (Brown et al. 2014; Ananda \& Herath 2003).

Delimiting heritage boundaries is facilitated by the use of Geographic Information Systems (GIS), which can handle spatial (and non-spatial) data on the topography, geomorphology and elevation of heritage sites (Orsi et al. 2013; Yang et al. 2014). Combined with the social and cultural contexts and views of local residents, GIS can help inform comprehensive judgments about how to delimit a specific heritage site boundary. As such it has been used to draw heritage site boundaries in previous studies. There have been few applications, however, that combine game theory and GIS to study the process of boundary-making in MNHs, with no prior studies applying a multi-objective game model to determine MNHs' boundaries. This marks an interesting opportunity for additional research.

This paper will apply game theory to consider the interests of various stakeholders in the process of setting boundaries for heritage sites. We use a multiobjective programming model to confirm a potential boundary interval for a mountain heritage site, considering stakeholders' values as a source of friction. Based on this identified boundary interval and using GIS, we determine a continuous, single, and appropriate boundary for the site that aligns with the relevant terrain, landforms, elevation, and land gradient. This study thus provides a scientific basis for setting the boundaries of $\mathrm{MNH}$, offering insights for heritage protection management, further developing the study of boundary-making and delivering a key reference for future research on MNHs.

\section{Theory}

\section{Multi-objective programming model}

The original multi-objective programming model (also known as multi-objective optimization or Pareto optimization) was put forward by the French economist Vilfredo Pareto in 1986 and has since been applied in diverse fields, including economics, management, military, science and engineering (Brown et al. 
2014; Sinha et al. 2013). The theory behind the model is that it allows comparing and resolving contradictions between multiple aims to obtain a non-inferior solution to a given conflict.

The multi-objective programming model includes objectives and constraints. The objective function is given by

$$
\begin{gathered}
\operatorname{Max} Z(X)=\left[Z_{1}(x), Z_{2}(x), \ldots, Z_{p}(x)\right], \\
\text { s.t.g } g_{j}(x) \leq 0, j=1,2, \ldots, m, \\
x_{k} \geq 0, k=1,2, \ldots, n .
\end{gathered}
$$

Where, $p, m$, and $n$ are the number of variables, $Z_{1}(x), Z_{2}(x), \ldots, Z_{p}(x)$ are the $p$ objective functions, $g_{j}(x)$ is the $f^{\text {th }}$ constraint condition, and $x_{k}$ is the $k^{\text {th }}$ decision variable. In this paper, a bi-objective model is used, aiming to best obtain the maximum economic value (EV) of unprotected land via a smaller heritage site area (PreA) and maximum ecological value (ESV) via a larger PreA. Taking account of environmental, social, economic and land use / land cover concerns, the above objective function can be expressed as

$$
\begin{aligned}
& \operatorname{MaxEV}=Z_{1}(x), \\
& M a x E S V=Z_{2}(x) .
\end{aligned}
$$

A game-theoretic model of the boundary-setting process

There are six basic elements of game theory: players, actions, information, strategies, payoffs, outcomes, and equilibrium (Zhang 2004). In this context, the initial boundary delimitation is the result of a game played between the local government and the expert scholars (Zhang 2008). We focus on these two groups as the players and define them as rational actors who will always choose the better solution when facing two or more choices.

The elements of the game model are as follows: players are the local government and the expert scholars, and the actions are players' choices in the process of setting the heritage site's boundary. The strategies reflect that in order to obtain the maximum economic value $\left(E V_{\text {max }}\right)$ from the unprotected land, the local government will fight for the minimum heritage site area $\left(\operatorname{Pre} A_{\text {min }}\right)$; in contrast, the scholars aim to obtain the maximum ecological value $\left(E S V_{\text {max }}\right)$ via the maximum heritage site area $\left(\operatorname{Pre} A_{\text {max }}\right)$. The payoff functions are the economic value function $E V=Z_{1}(x)$ and the ecological value function $E S V=Z_{2}(x)$. The decision variables are land use / land cover types $x_{k}$.

Originally, aiming to obtain the optimal solution for each single objective, the local government and the scholars each want to know the other's Pre $A$ to obtain the corresponding EV and ESV. The initial benefit values for $E V$ and $E S V$ are defined by the interval between payoffs and negotiation between the two sides.
For each participant, the benefit function for EV or ESV is

For local government: $\mathrm{EV}_{\min } \leq \mathrm{EV}=\mathrm{Z}_{1}(\mathrm{x}) \leq \mathrm{EV}_{\max }$;

For scholars: $\mathrm{ESV}_{\min } \leq \mathrm{ESV}=\mathrm{Z}_{2}(\mathrm{x}) \leq \mathrm{ESV}_{\max }$.

The initial result of the multi-objective game model contains a pair of values of $Z_{1}(x)$ and $Z_{2}(x)$ for each participant. Once the value expectation range is confirmed, the initial round of bargaining begins. Each player provides their anticipated economic or ecological value as respective game goal, that is, $E V_{\text {goal }}$ and $E S V_{\text {goal }}$ According to their goals for economic and ecological benefits and the actual natural conditions of the heritage site area (captured by $a$, the minimum area of core value of the heritage site, and $A$ the total area under study), each player determines a protected area $\left(x_{k}\right)$ and spatial distribution of the various land use / land cover types (Dai et al. 2012). For the local government, the strategy is

so that

$$
\operatorname{MaxEV}=\mathrm{Z}_{1}(\mathrm{x})
$$

$$
\begin{gathered}
g_{j}(x) \leq 0, j=1,2, \ldots, \\
Z_{2}(x) \geq \operatorname{ESV}_{\text {goal }}, \\
a \leq \operatorname{PreA}_{\text {min }}=\operatorname{Min}_{(k=1)}^{n} x_{k} \leq A, \\
x_{k} \geq 0, k=1,2, \ldots, a .
\end{gathered}
$$

For the scholars, the strategy is

so that

$$
\operatorname{MaxESV}=\mathrm{Z}_{2}(\mathrm{x})
$$

$$
\begin{gathered}
\mathrm{g}_{\mathrm{j}}(\mathrm{x}) \leq 0, \mathrm{j}=1,2, \ldots, \mathrm{m}, \\
\mathrm{Z}_{1}(\mathrm{x}) \geq \mathrm{EV}_{\text {goal }}, \\
\mathrm{a} \leq \operatorname{PreA}_{\max }=\underset{(\mathrm{k}=1)}{\operatorname{Max} \sum_{\mathrm{k}}^{\mathrm{n}} \leq \mathrm{A},} \\
\mathrm{x}_{\mathrm{k}} \geq 0, \mathrm{k}=1,2, \ldots, \mathrm{n} .
\end{gathered}
$$

In the initial phase neither player will be satisfied with the results arising from the other's objective. The objective value of this result to each player is far below their goal: the local government expected the scholars' Pre $A$ to be much smaller, and the EV of the unprotected land did not meet their goal, whereas the scholars expected the local governments' Pre $A$ to be much larger, and the ESV was less than their goal. Thus, the players begin a series of bargaining rounds. This bargaining process must assume the success of the heritage declaration project as its final result (i. e., the bargaining model must succeed in analysing the actors' relationships), so each player will need to make concessions before achieving a Nash equilibrium at which all players' goals remain close to $E V_{\text {max }}$ and $E S V_{\text {max }}$. 


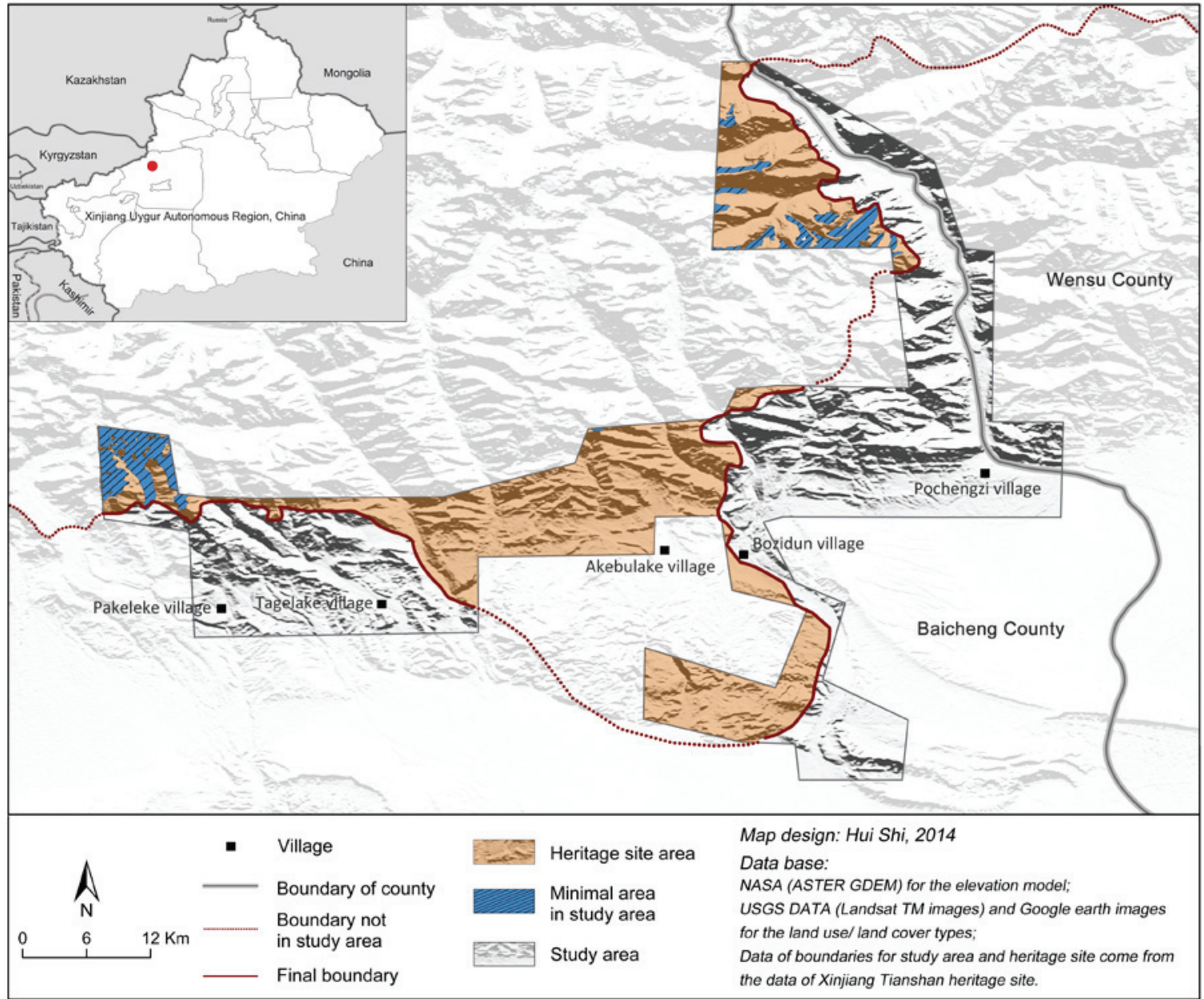

Figure 1-Map of the study area.

The bargaining rounds involve the local government increasing their goal Pre $A$ and reducing their economic benefit from the unprotected land and the scholars decreasing their goal Pre $A$ and reducing their ecological benefit from the protected land. Throughout this game process both sides lower their earnings expectations until the $n$th round, in which there is little difference in PreA between two sides and the corresponding $E V$ and ESV are also similar. At this point both sides agree with the economic value $\left(E V^{*}\right)$ and ecological value $\left(E S V^{*}\right)$ as follows:

For local government: $\mathrm{EV}^{*} \geq \mathrm{EV}_{\text {goal }}$;

For scholars: $\mathrm{ESV}^{*} \geq \mathrm{ESV}_{\text {goal }}$.

This pair of solution values $\left(\mathrm{EV}^{*}, \mathrm{ESV}^{*}\right)$ is defined as the Nash equilibrium.

To sum up, the multi-objective game model first aims to confirm the range of payoffs and benefits for each stakeholder before trying to obtain the interval of Nash equilibrium values that satisfy both sides. Before the game obtains agreement from both sides, each player sets independent goals for their respective values, bargaining with one another until they agree. This agreement occurs at the Nash equilibrium val- ues. Within this game process the difference between boundary delimitation of $\mathrm{MNH}$ s and that of other types of heritage sites is captured in that the determination of Pre $A$ must consider the various types of land use / land cover and how these change, based on characteristics like elevation and terrain.

Having established this theoretical model, we will now apply it to a relevant case study: Xinjiang Tianshan, a mountain area in China's far west.

\section{Empirical application}

\section{Case study area}

Xinjiang Tianshan was listed as a Natural World Heritage Site in 2013, becoming the $44^{\text {th }}$ World Heritage Site in China. Tomur, a component of the Xinjiang Tianshan Heritage Site, is the focus of this case study. Stakeholders involved in setting the boundary of Tomur include expert scholars, central and local government actors, a local management committee and conservationists. Among them, the local government and the scholars are the most important participants in the boundary-making process and have differing views regarding boundary delimitation of the heritage site. We thus chose the local government (the main manager of the Tomur area) and the scholars 
Table 1 - Equivalent factors of EV and ESV for different land use/land cover types in the study area.

\begin{tabular}{|l|r|r|r|r|r|r|r|r|}
\hline Equivalent factor & Woodland & Grassland & $\begin{array}{l}\text { Cultivated } \\
\text { land }\end{array}$ & $\begin{array}{l}\text { Settlement/in- } \\
\text { frastructure land }\end{array}$ & Water & $\begin{array}{l}\text { Unused } \\
\text { land }\end{array}$ & $\begin{array}{l}\text { Glacier } \\
\text { Potential mineral } \\
\text { economic value (E) }\end{array}$ \\
\hline (yuan*hm ${ }^{-2 *} \mathrm{a}^{-1}$ ) & $\left(\mathrm{x}_{1}\right)$ & $\left(\mathrm{x}_{2}\right)$ & $\left(\mathrm{x}_{3}\right)$ & $\left(\mathrm{x}_{4}\right)$ & $\left(\mathrm{x}_{5}\right)$ & $\left(\mathrm{x}_{6}\right)$ & $\left(\mathrm{x}_{7}\right)$ & \\
\hline EV & 5908.78 & 297.55 & 1311.30 & 76974.95 & 2129.35 & 0 & 0 & 246.91 \\
\hline ESV & 27560.78 & 9132.27 & 8716.02 & 0 & 57984.86 & 529.77 & 13.43 & 0 \\
\hline
\end{tabular}

(experts who have undertaken considerable research into Tomur's heritage value) as the players in the multiobjective game model we used to examine the process of boundary delimitation (Yang et al. 2013).

In the process of boundary delimitation the UNESCO operational guidelines must be consulted. According to these criteria the heritage site must contain a region of outstanding universal value (in this case, special geological features and a glacier), a vertical natural zone and a buffer region. The buffer region helps alleviate excessive pressure on heritage sites (Paulo et al. 2014). In the actual process of boundary setting the local government and the scholars have obvious conflicts in balancing local economic development against environment protection. They must protect a minimum area (PreA) because of the requirement to preserve the core heritage value, but are in dispute about the buffer boundary of the heritage site. In this paper we consider this disputed area to be that situated between latitudes $41^{\circ} 31^{\prime} 28^{\prime \prime}$ to $42^{\circ} 9^{\prime} 46^{\prime \prime}$ and longitudes $80^{\circ} 84^{\prime} 3$ " to $80^{\circ} 59^{\prime} 4^{\prime \prime}$ (Figure 1). The total disputed area is 121498.6 hectares (ha), located in Wensu County in the Xinjiang Uygur Autonomous Region and belonging to the South Tianshan mountain region. The region includes alpine meadow and desert ecosystems typical of Xinjiang Tianshan's south slope and representative of outstanding natural beauty, including a snowy mountain glacier and a multi-layered red canyon (Xu et al. 2012).

Estimating the EV and ESV of land in the study area

The EV and ESV were calculated as the product between the land areas and the corresponding equivalent factors for the respective land use / land cover types. According to Landsat TM remote sensing images with a spatial resolution of $30 \mathrm{~m}$, the physical situation of the study area, climate characteristics, national land use / land cover classification criteria and Google earth images, the area was classified into several land use / land cover types: woodland, grassland, cultivated land, construction land, unused land and glacier.

The EV of different land use / land cover types refers to the output value of production on these land use / land cover types in a given year. The output values for the different land use / land cover types were calculated using their corresponding gross economic sectors' output values in Wensu County in 2010. For instance, the EV of woodland was calculated as the value of the forestry sector's output divided by the woodland area of Wensu County in 2010. EV equiva- lent factors for other land use / land cover types, such as grassland, cultivated land, construction land, water areas and unused land, were calculated using the output values of the corresponding sectors, such as animal husbandry, farming, secondary and tertiary industry, and fisheries.

In addition, the economic value included the added value of mineral resources. In the study area there is no mining activity, but there may be potential unexploited mineral resources. For Wensu County, mineral extraction profits are an important source of revenue that can be used to develop the economy. In the game process Wensu County's government must thus consider the potential economic value of mineral resources in the unprotected land. This potential value is calculated as the product between the average added value of potential mineral resource development per unit area and the area of the unprotected zone. The estimate is based on the potential mineral exploration of a given resource for a fixed number of years and that resource's extent in Wensu County (Table 1). The source data were taken from Xinjiang Statistical Yearbook for 2011, Aksu Prefecture Statistical Yearbook for 2011 and Aksu Prefecture's Statistical Bulletin of National Economic and Social Development from 2010.

The ESV was estimated following the ecosystem service value method. Ecosystem service value captures the value that humans derive directly and indirectly from an ecosystem. This includes the value of the processes through which the ecosystem inputs useful materials and energy to the economic and social systems, receives and transforms waste created by the economic and social systems, and directly provides services to members of society. It includes both monetary value and use value. Although ecosystem service value contains the direct market value, this is different from the economic value expected by the local government: the direct market value of the ecosystem refers to its total potential economic value, whereas the economic value refers to the production output in the chosen year (Fan \& Shibata 2014; Bernues et al. 2014).

Xie et al. (2010), following Costanza's method (Costanza et al. 1997), created the equivalent factor table for Chinese ecosystem services. Some scholars then used these for deep research on ecosystem service in Xinjiang (Zhou et al. 2004; Huang, 2012). In this paper the equivalent values of ESV used are those quoted by Huang (2012), because the author modified and estimated the ecosystem service value equivalents for different land use / land cover types in Xinjiang. The ecosystem services research for different land 
Table 2 - Land use / land cover constraints in the study area, as included in the multi-objective programming model.

\begin{tabular}{|l|l|}
\hline Model component & Function \\
\hline Goals & \multicolumn{2}{|l|}{} \\
\hline 1. Economic value & $Z_{2}(x)=5908.78 x_{1}+297.55 x_{2}+1311.30 x_{3}+76974.95 x_{4}+2129.35 x_{5}+0 x_{6}+0 x_{7}+E$ \\
\hline 2. Ecological service value & $Z_{1}(x)=27560.78 x_{1}+9132.27 x_{2}+8716.02 x_{3}+0 x_{4}+57984.86 x_{5}+529.77 x_{6}+13.43 x_{7}$ \\
\hline 3. Potential economic value & $\begin{array}{l}E=246.91 *\left(121498.6-x_{1}-x_{2}-x_{3}-x_{4}-x_{5}-x_{6}-x_{7}\right) \\
\text { Note: assuming that the potential mineral development production value is RMB } 30 \text { million per year in the } \\
\text { study area }\end{array}$ \\
\hline Constraints (ha) & $8210 \leq x_{1}+x_{2}+x_{3}+x_{4}+x_{5}+x_{6}+x_{7} \leq 121498.6$ \\
\hline 1. Land availability & $667 \leq x_{1} \leq 9266.1$ \\
\hline 2. Woodland & $2743 \leq x_{2} \leq 87482.4$ \\
\hline 3. Grassland & $x_{3} \leq 3329$ \\
\hline 4. Cultivated land & $x_{4} \leq 60$ \\
\hline $\begin{array}{l}\text { 5. Settlements/infrastruc- } \\
\text { ture land }\end{array}$ & $x_{5} \leq 20.1$ \\
\hline 6. Bodies of water & $372 \leq x_{6} \leq 16890$ \\
\hline 7. Unused land & $x_{7}=4427.6$ \\
\hline 8. Glacier & $x_{1}, x_{2}, x_{3}, x_{4}, x_{5}, x_{6}, x_{7} \geq 0$ \\
\hline 9. Non-negativity &
\end{tabular}

use / land cover types of Huang (2012) is similar to the study region. Among these, glacier land was classified separately from unused land. The Tomur glacier, as the largest glacier in Tianshan, is the core feature that deserves protection for its heritage value. The equivalent factor for the glacier is assessed in terms of glacial water reserves, determined via the shadow engineering method (Ouyang et al. 1999), according to its role in regulating climate, water conservation, biodiversity conservation and landscape aesthetics (Zhao et al. 2009).

\section{Land use / land cover constraints}

Local government and scholars calculate the EV and ESV arising from different PreAs and the corresponding values of these land use / land cover types. Given the players' different goals, there are certain constraints on land use / land cover types, as listed in Table 2. The first is land availability: in order to ensure the integrity of the vertical natural heritage site and protect the glacier (i. e. the region of central heritage value), the minimum area must not be less than that of the glacier, whereas the maximum area cannot exceed the total area of the study region. Second, areas of woodland, grassland, cultivated land and unused land are constrained by their current distribution in the study area. Third, the area of the glacier corresponds to the area of central heritage value. Finally, all land areas must be non-negative.

Land use/land cover varies across the elevation gradient, with the glacier appearing in high-altitude areas, the bare rock in medium- and high-altitude areas, grassland distributed across altitudes but chiefly in medium- and low-altitude areas, and settlement and infrastructure areas, cultivated and unused land all distributed in low-altitude areas. Therefore, given a change in $\operatorname{Pre} A$, the corresponding land use / land cover types will change depending on the mountain elevation, slope, aspect, and other geographic characteristics.

Given these conditions and constraints, we now test our game theoretic model within this case study context.

Table 3 - Players' strategic aims in the case study.

\begin{tabular}{|c|c|c|c|c|}
\hline Bargaining process & \begin{tabular}{|l}
$\begin{array}{l}\text { Goals } \\
\text { (million yuan) }\end{array}$ \\
\end{tabular} & $\begin{array}{l}\text { Local government for EV } \\
\text { Set goal } Z_{1} \text { (million yuan) }\end{array}$ & $\begin{array}{l}\text { Scholars for ESV } \\
\text { Set goal } Z_{2} \text { (million yuan) }\end{array}$ & $\begin{array}{l}\text { Heritage area } \\
\text { PreA (ha) }\end{array}$ \\
\hline \multicolumn{5}{|l|}{ Initial } \\
\hline \# 0-1 & $Z_{1}=114.86$ & 114.86 & 43.76 & 8210 \\
\hline \# 0-2 & $Z_{2}=929.81$ & 13.19 & 929.81 & 101483 \\
\hline \multicolumn{5}{|l|}{$1^{\text {st }}$} \\
\hline \# 1-1 & $Z_{1}=100.00$ & 100 & 189.43 & 24387 \\
\hline \# 1-2 & $Z_{2}=800.00$ & 27.91 & 800 & 85232 \\
\hline \multicolumn{5}{|l|}{$2^{\text {nd }}$} \\
\hline \# 2-1 & $\mathrm{Z}_{1}=80.00$ & 80 & 377.27 & 45231 \\
\hline \# 2-2 & $Z_{2}=660.00$ & 42.83 & 660 & 72730 \\
\hline \multicolumn{5}{|l|}{$3^{\text {rd }}$} \\
\hline \# 3-1 & $Z_{1}=64.00$ & 64 & 471.76 & 52135 \\
\hline \# 3-2 & $Z_{2}=600.00$ & 51.49 & 600 & 63761 \\
\hline \multicolumn{5}{|l|}{$4^{\text {th }}$} \\
\hline \# 4-1 & $Z_{1}=60.00$ & 60 & 516.18 & 55897 \\
\hline \# 4-2 & $Z_{2}=500.00$ & 61.96 & 500 & 54697 \\
\hline
\end{tabular}


Table 4 - Results of game bargaining in the case study.

\begin{tabular}{|c|c|c|c|c|c|c|c|c|c|c|c|c|}
\hline \multirow{3}{*}{$\begin{array}{l}\text { Bargaining } \\
\text { proces }\end{array}$} & \multirow[t]{3}{*}{ Goal } & \multicolumn{11}{|c|}{ Solutions } \\
\hline & & $Z_{1}(E V)$ & $Z_{2}$ (ESV) & PreA & $\begin{array}{l}\text { Wood- } \\
\text { land }\left(x_{1}\right)\end{array}$ & $\begin{array}{l}\text { Grassland } \\
\left(\mathrm{x}_{2}\right)\end{array}$ & $\begin{array}{l}\text { Cultivated } \\
\text { land }\left(x_{3}\right)\end{array}$ & $\begin{array}{l}\text { Settlements/in- } \\
\text { frastructure } \\
\text { land }\left(x_{4}\right)\end{array}$ & Water $\left(x_{5}\right)$ & $\begin{array}{l}\text { Unused } \\
\text { land } \\
\left(x_{6}\right)\end{array}$ & Glacier $\left(x_{7}\right)$ & $\begin{array}{l}\text { Potential } \\
\text { mineral } \\
\text { value }(E)\end{array}$ \\
\hline & & $\begin{array}{l}\text { million } \\
\text { yuan }\end{array}$ & $\begin{array}{l}\text { million } \\
\text { yuan }\end{array}$ & (ha) & (ha) & (ha) & (ha) & (ha) & (ha) & (ha) & (ha) & $\begin{array}{l}\text { million } \\
\text { yuan }\end{array}$ \\
\hline \multicolumn{13}{|l|}{ Initial } \\
\hline \#0-1 & $Z_{1}=11486$ & 114.86 & 43.76 & 8210 & 667 & 2743 & 0 & 0 & 1.2 & 372 & 4427 & 27.97 \\
\hline$\# 0-2$ & $Z_{2}=92981$ & 13.19 & 929.81 & 101483 & 9266.09 & 70000 & 3000 & 50 & 20 & 14720 & 4427 & 4.94 \\
\hline \multicolumn{13}{|l|}{$1^{\text {st }}$} \\
\hline$\# 1-1$ & $z_{1}=10000$ & 100 & 189.43 & 24387 & 1800 & 15000 & 100 & 5 & 5 & 3050 & 4427 & 23.98 \\
\hline$\# 1-2$ & $Z_{2}=80000$ & 27.91 & 800 & 85232 & 8400 & 60000 & 1600 & 40 & 15 & 10750 & 4427 & 8.95 \\
\hline \multicolumn{13}{|l|}{$2^{\text {nd }}$} \\
\hline \#2-1 & $Z_{1}=8000$ & 80 & 377.27 & 45231 & 3500 & 30000 & 300 & 6 & 8 & 6990 & 4427 & 18.83 \\
\hline$\# 2-2$ & $Z_{2}=66000$ & 42.83 & 660 & 72730 & 7000 & 49000 & 1500 & 38 & 14.5 & 10750 & 4427 & 12.04 \\
\hline \multicolumn{13}{|l|}{$3^{\text {rd }}$} \\
\hline \#3-1 & $Z_{1}=6400$ & 64 & 471.76 & 52135 & 5200 & 35000 & 500 & 6 & 12 & 6990 & 4427 & 17.13 \\
\hline \#3-2 & $Z_{2}=60000$ & 51.49 & 600 & 63761 & 6500 & 45000 & 800 & 20 & 14 & 7000 & 4427 & 14.26 \\
\hline \multicolumn{13}{|l|}{$4^{\text {th }}$} \\
\hline \#4-1 & $Z_{1}=6000$ & 60 & 516.18 & 55897 & 5750 & 38000 & 700 & 6 & 14 & 7000 & 4427 & 16.2 \\
\hline$\# 4-2$ & $Z_{2}=50000$ & 61.96 & 500 & 54697 & 5700 & 37000 & 650 & 8 & 12 & 6900 & 4427 & 16.49 \\
\hline
\end{tabular}

\section{Results}

Initial goals and strategy

In the study area, the glacier must be protected and thus forms the minimum area for the site. The maximum area is the study area. As such, the area range within which the game can be played is 8210 ha $\leq$ PreA $\leq 121498.6$ ha.

In the process of boundary delimitation the strategic goals of the local government and scholars are shown in Table 3. The initial goal of the local government is denoted by \#0-1, and that of the scholars by \#0-2. In the initial phase for the local government, Pre $A$ is 8210 ha (the minimum area), and the economic benefit from the unprotected land is 114.86 million yuan; for scholars, the initial $\operatorname{Pre} A$ is 101483 ha, with the ecological benefit of the region valued at 929.81 million yuan.

The local government's initial goal for PreA corresponds to an ESV of 43.76 million yuan, far below the scholars' expected ESV (929.81 million yuan). Meanwhile, for the scholars, the $E V$ corresponding to the initial PreA goal is 13.19 million yuan, much less than that expected by the local government (114.86 million yuan). The boundary delimitation process thus begins with large differences between the two players' expected benefits.

\section{Bargaining process}

In each round of the game process the players each lower their expectations according to the obtained $E V$ and ESV in order to reach the final equilibrium values after four rounds of bargaining. These results are shown in Table 4.

In the first bargaining round the local government reduces their $E V$ to 100 million yuan (Pre $A$ increases to 24387 ha, ESV increases to 189.43 million yuan) while the scholars reduce their ESV to 800 million yuan (PreA decreases to 85232 ha, EV increases to 27.91 million yuan in unprotected land), but each actor's achieved goal is far from their initial goal. Neither player is satisfied with the results of the first bargaining round, so they continue to bargain.

\section{Nash equilibrium}

In the fourth round the local government's economic value goal has fallen from 114.86 million yuan to 60 million yuan, while the scholars' ecological value goal has decreased from 929.81 million yuan to 500 million yuan. The government's Pre $A$ has increased from 8210 ha to 55897 ha, and that of the scholars has decreased from 101483 ha to 54697 ha. There is now only a small difference between the PreAs proposed by the local government and the scholars. The economic value suggested by the scholars exceeds the expectation of the local government, and the ecological value proposed by the government is higher than that expected by the scholars. As such, they have reached a Nash equilibrium.

The results of this bargaining process are shown in Figure 2. The range of Nash equilibrium economic values is 60-61.96 million yuan, the corresponding range of ecological values is $500-516.18$ million yuan, and the range of heritage area (PreA) is 54697-55897 ha.

Changes in the decision variables (land use/land cover types) directly influence the benefits to the local government and scholars (Table 4). In the final equilibrium of the game the boundary of the government's $\operatorname{Pre} A$ is extended into low-elevation areas, so the largest increase in area comes from grasslands (alpine meadow class). The boundary of the scholars' Pre $A$, in 


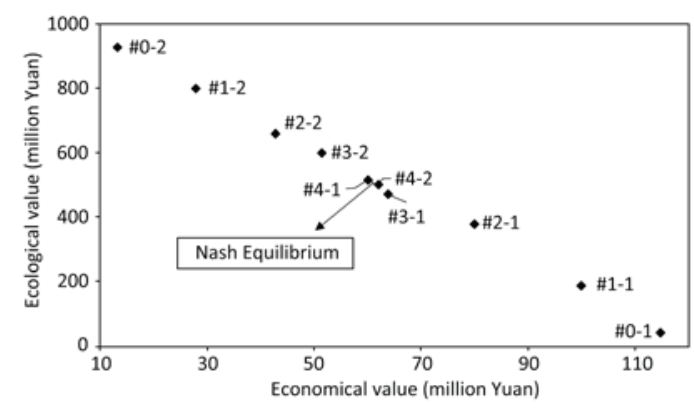

Figure 2 - Results of multi-objective programming analysis.

contrast, contracts from low- to high-elevation areas, so the areas of woodland, grassland, cultivated land and settlement/infrastructure land all shrink. The largest declines in area are for woodland and grassland. Among all land use / land cover types, the glacier is the core heritage value and is fully protected. Thus the game is largely a struggle for grassland and woodland, which have considerably more economic and ecological value than other land types. In the boundary delimitation process, both actors make concessions in area by sacrificing grassland and woodland. When they achieve the Nash equilibrium, there are thus limited differences in the two players' goals for grassland and woodland areas.

Decision-making

Throughout the game the stakeholders constantly adjust their own goals according to their respective economic and ecological values. After each round of bargaining the difference between their goals shrinks until they eventually achieve mutually satisfying results. In the multi-objective programming model, the Nash equilibrium results provide a narrow space within which the players can reach a decision. They can choose to continue to bargain within the Nash equilibrium range or accept the game equilibrium result. The Nash equilibrium space thus enables the players to make reasonable judgments based on their economic and ecological values and confirm an appropriate boundary.

In this case study the Nash equilibrium range of areas, acceptable to both the local government and the scholars, was 54697-55897 ha. The final boundary will be chosen within this Nash equilibrium space by considering geographic aspects, such as water features, valley ridges and elevation contours. In order to obtain a consistent boundary, the results of field investigations and the protection of vegetation, soil, biodiversity and geological diversity must all be considered to reach an eventual boundary defining the Tomur buffer region in Xinjiang Tianshan Natural Heritage Site.

\section{Discussion}

Aiming to protect the integrity of a mountain natural heritage site, this paper considered stakeholders' diverse values for land use / land cover types. A multi-objective game model was created to determine a reasonable boundary range. The basic principle of the model was that by altering the amount of different land use / land cover types within the protected area, the players could bargain with one another according to their expected benefits. A range of potential boundaries that satisfied all players' interests was confirmed in the form of the Nash equilibrium interval. Combining this with a consideration of geomorphic features based on a field investigation, we obtained a final boundary for the Tomur buffer region.

Previous studies have mainly focused on the geographic characteristics of boundary making, the relationships between the boundary and local residents, and the relationships among stakeholders (Allendorf 2007; Pierce et al. 2005; Wimmer 2009). Little research into the process of delimiting reasonable boundaries for heritage sites has used a multi-objective game model that considers the perspectives of stakeholders and their expected benefits, as done here. In this study we used land use / land cover types as constraints on potential benefits, used land use / land cover type distributions to verify the rationality of the proposed boundary and defined the actual boundary based on geographic characteristics (Freemark et al. 2002). The approach aligns with methods for defining heritage site boundaries: Yeh (2003) suggested that geographic features form the basic elements of boundary making. The significance of this paper lies in finding a scientific and reasonable method to determine the boundary of a MNHs from the perspective of game theory. The method accurately reflects the process of setting heritage site boundaries as a game between local government and scholars under the constraints of land use / land cover area. The boundary proposed via this method is almost identical to the final boundary submitted to UNESCO for the Tomur buffer area, which is strong evidence of the method's effectiveness.

There are some limitations to this analysis. Our multiobjective game model, in accordance with past research, was based on the assumption that the local government and the scholars are the only two rational actor stakeholders (Zhang 2004). In the actual boundary delimitation process, however, central government, local residents, local committees and protection organizations could affect the scope of the final boundary (Spang et al. 2012). Further, the local government's choice could be more complicated, considering not only economic development but also environmental protection benefits and the value of the heritage site. Similarly, scholars might pay attention to local economic development as well as environmental protection (Zhang 2008). This paper thus simplified the game process, as restricting each player to achieving a single goal was helpful for building the model. However, it also reflects the general positions of environmental stakeholders in China and explains the essential conflict in the conservation process (Wei 2007). 
Based on achieving Pareto optimality in a multi-objective game model, this paper did not obtain a final solution but rather a narrow interval of Nash equilibrium values. Previous research has considered stakeholder benefits via revenue functions, but the constraints placed on these revenue functions had no spatial characteristics; the Pareto result was expressed as a single solution (Sinha et al. 2013; Liu 2011). In the game process used in this paper the multi-objective game model has numeric attributes, excluding the spatial properties of the land use / land cover types. This is because the multi-objective game model with spatial properties is much more complex than the existing model, and we have so far been computationally unable to add the spatial attributes to the multi-objective model. To compensate for this shortcoming, we first calculated the protected area range for various types of land use / land cover using the multi-objective game model; the specific boundary was then chosen by referencing the spatial distribution of the land use / land cover types.

Indeed, the local government and scholars did consider the spatial attributes of land use / land cover types in the bargaining process. For instance, the glacier (the essential area to protect) spread across highaltitude areas. The grassland and woodland areas, considering diversity and the geography of mountainous zones, extended across in medium- and low-altitude areas. Cultivated land and settlement/infrastructure land, closely related to human activities, were located in low-altitude areas. In the bargaining process the protected area expected by scholars was required to shrink from low- to high-altitude regions to protect the core value of the heritage site while that expected by the local government gradually extended into mediumand low-altitude areas. The bargaining process thus did have spatial attributes, but only the areas of land use / land cover types were defined as constraints on the final boundary. In other words, this paper considered the spatial properties of land use / land cover to some extent, but the spatial properties were not shown in the multi-objective model. Ultimately, using GIS, the final boundary was determined by combining the geographic concerns with the Nash equilibrium space. In this process boundary delimitation also considered the spatial properties of different land use / land cover types, including landscape integrity and connectivity. In future research, we will attempt to comprehensively consider the value orientations of various stakeholders, combining these with spatial properties of land use / land cover types and local cultural values to obtain more socially acceptable boundaries.

In the process of heritage site declaration setting an appropriate boundary is essential for protecting the integrity and authenticity of wildlife habitats, ecological services and geological features of the heritage site (Gillespie 2013). Understanding both an area's heritage value and the relationships among stakeholders is essential in boundary delimitation, as the heritage value can only be protected with a reasonable boundary.
If the boundary does not comprehensively consider these interrelated elements, the region chosen may not satisfy the necessary conditions for preserving heritage value and there will be future problems with protection and management. Only when it integrates the interests of all stakeholders and protects the heritage value will a boundary be sustainable. Thus the boundary chosen here would not actually be adopted by policymakers: the process of boundary making requires iterative discussions that engage diverse government departments, experts and environmental groups. After satisfying the opinions of all sides and having international experts conduct an investigation, the final boundary could be confirmed. Even so, this study has contributed insights that can aid heritage site research, protection and management.

\section{Conclusion}

This paper has simulated the process of defining the boundaries of China's Tomur buffer zone using a multi-objective model of a game between local government and scholars, spatial analysis of land use types, and a field survey. In creating the model the local government's goal was to maximize the economic value of the unprotected land, while the scholars aimed to maximize the ecological value of the heritage site. After several rounds of bargaining a final Nash equilibrium interval was achieved. Combining this with geomorphic features, as discerned through a field investigation, we obtained a final boundary. The results showed that such a simulation process could constitute a scientific method for boundary making in MNHs. This adds greatly to research on heritage site boundaries and provides a theoretical foundation for future scholarship.

In subsequent studies researchers should consider closely the value orientations of various stakeholders, combining this with knowledge of local cultures and customs, solicited from the perspectives of residents, to obtain an appropriate boundary. By fully considering the relationships among the local economy, ecology, residents and culture, an optimal choice can be made that balances the interests of all stakeholders in the heritage site declaration process. This process of boundary delimitation needs to be continually investigated, discussed, reinvestigated and re-discussed, as boundary delimitation plays a crucial role in the management of the heritage site later and in the protection of its surrounding environment.

\section{Acknowledgements}

The study was supported by the Western PhD project at the University of Chinese Academy of Sciences (XBBS201210), National Natural Science Foundation (No. 41301163), Chinese Academy of Sciences Visiting Professorship for Senior International Scientists (No. 2013T2Z0004). 


\section{References}

Allendorf, T.D. 2007. Residents' attitudes toward three protected areas in southwestern Nepal. Biodiversity and Conservation 16 (7): 2087-2102. Mazomanie.

Ananda, J. \& G. Herath 2003. The use of Analytic Hierarchy Process to incorporate stakeholder preferences into regional forest planning. Forest Policy and Economics 5 (1): 13-26. Wodonga.

Bernues, A., O.T. Rodriguez, B.R. Ripoll et al. 2014. Socio-Cultural and Economic Valuation of Ecosystem Services Provided by Mediterranean Mountain Agroecosystems. Plos One 9 (7): e102479. Portugal.

Binmore, K. 2010. Game theory and institutions. Journal of Comparative Economics 38 (3): 245-252. Bristol.

Brown, M., B. An, C. Kiekintveld, et al. 2014. An extended study on multi-objective security games. $A u$ tonomous Agents and Multi-Agent Systems 28 (1): 31-71. Los Angeles.

Chen, Y. 2005. The decision-making and influence of world heritage designation: a case study of ancient villages in Southern Anbui (XJdi and Hongcun) and Danxia Mountain in Guangdong. Guangzhou.

Costanza, R., R. d'Arge, R. de'Groot et al. 1997. The value of the world's ecosystem services and natural capital. Nature 387 (6630): 253-260. Solomons.

Dai, L.M., Y. Wang, B.J. Lewis et al. 2012. The trend of land-use sustainability around the Changbai Mountain Biosphere Reserve in northeastern China: 19772007. International Journal of Sustainable Development and World Ecology 19 (4): 369-377. Shenyang.

Fan, M. \& H. Shibata 2014. Spatial and Temporal Analysis of Hydrological Provision Ecosystem Services for Watershed Conservation Planning of Water Resources. Water Resources Management 28 (11): 3619_ 3636. Sapporo.

Ford, R.T. 1999. Law's territory - (A history of jurisdiction). Michigan Law Review 97 (4): 843-930. Ann Arbor.

Fox, J. 2002. Siam mapped and mapping in Cambodia: Boundaries, sovereignty, and indigenous conceptions of space. Society \& Natural Resources 15 (1): 65-78. Philadelphia.

Freemark, K., D. Bert \& M.A. Villard 2002. Patch-, landscape-, and regional-scale effects on biota. Applying Landscape Ecology in Biological Conservation: 58-83. Hull.

Gillespie, J. 2013. World Heritage management: boundary-making at Angkor Archaeological Park, Cambodia. Journal of Environmental Planning and Management 56 (2): 286-304. Sydney.

Gullino, P. \& F. Larcher 2013. Integrity in UNESCO World Heritage Sites. A comparative study for rural landscapes. Journal of Cultural Heritage 14 (5): 389-395. Grugliasco.

Guthery, F.S. \& J.H. Shaw 2013. Density dependence: Applications in wildlife management. Journal of Wildlife Management 77 (1): 33-38. Stillwater.
Han, F., Z.P. Yang, H. Wang et al. 2011. Estimating willingness to pay for environment conservation: a contingent valuation study of Kanas Nature Reserve, Xinjiang, China. Environmental Monitoring and Assessment 180 (1-4): 451-459. Urumqi.

Han, F. 2011. Study on Protection and Management for Security of Mountain Natural Heritage: A Case Study of Kanas Nature Reserve, Xinjiang, China. Urumqi.

Hazen, H. 2008. "Of outstanding universal value": The challenge of scale in applying the World Heritage Convention at national parks in the US. Geoforum 39 (1): 252-264. St Paul.

Huang, F., S.X. Wu \& H. Tang 2012. Response of Ecological Environment to Land Use/Cover Change in Xinjiang during 1990-2008 based on Remote Sensing and GIS. Journal of Desert Research 32 (5): 14861493. Urumqi.

Jimura, T. 2011. The impact of world heritage site designation on local communities: A case study of Ogimachi, Shirakawa-mura, Japan. Tourism Management 32 (2): 288-296. York.

Lee, C.S. 2012. Multi-objective game-theory models for conflict analysis in reservoir watershed management. Chemosphere 87 (6): 608-613. Tainan.

Liu, X.Y. 2011. Technical Framework of Boundary Demarcation of Natural Heritage: a case study for Xinjiang Tianshan. Urumqi.

Moss, B. 2010. Climate change, nutrient pollution and the bargain of Dr Faustus. Freshwater Biology 55: 175-187. Merseyside.

Nash, J.F. 1950. The bargaining problem. Econometrica 18 (2): 155-162. Malden.

Orsi, F., D. Geneletti \& A. Borsdorf 2013. Mapping wildness for protected area management: A methodological approach and application to the Dolomites UNESCO World Heritage Site (Italy). Landscape and Urban Planning 120: 1-15. Trento.

Ouyang, Z.Y., X.K. Wang \& H. Miao 1999. A primary study on Chinese terrestrial ecosystem services and their ecological - economic values. Acta Ecologica Sinica 19 (5): 607-613. Beijing.

Paulo, A., A. Galas \& S. Galas 2014. Planning the Colca Canyon and the Valley of the Volcanoes National Park in South Peru. Environmental Earth Sciences 71 (3): 1021-1032. Krakow.

Pierce, S.M., R.M. Cowling, A.T. Knight et al. 2005. Systematic conservation planning products for landuse planning: Interpretation for implementation. Biological Conservation 125 (4): 441-458. Port Elizabeth.

Pomeroy, R. \& F. Douvere 2008. The engagement of stakeholders in the marine spatial planning process. Marine Policy 32 (5): 816-822. Groton.

Rao, K.S., S. Nautiyal, R.K. Maikhuri et al. 2003. Local peoples' knowledge, aptitude and perceptions of planning and management issues in Nanda Devi Biosphere Reserve, India. Environmental Management 31 (2): 168-181. Almora.

Ryan, C., C. Zhang \& Z. Deng 2011. The impacts of tourism at a UNESCO heritage site in China - a 
need for a meta-narrative? The case of the Kaiping Diaolou. Journal of Sustainable Tourism 19 (6): 747-765. Hamilton.

Shapley, L.S. 1953. Stochastic games. Proceedings of the National Academy of Sciences of the United States of America 39 (10): 1095-1100. Washington, DC.

Sinha, A., P. Malo, A. Frantsev et al. 2013. Multiobjective Stackelberg Game Between a Regulating Authority and a Mining Company: A Case Study in Environmental Economics. 2013 Ieee Congress on Evolutionary Computation: 478-485. Helsinki.

Spang, E., C.M. Lemieux \& S. Strobl 2012. Stakeholder engagement: A foundation for natural heritage systems identification and conservation in southern Ontario. Forestry Chronicle 88 (6): 686-696. Peterborough.

Su, M. \& B. Li 2012. Resource Management at World Heritage Sites in China. In: Ma, M. (ed.), 2011 International Conference of Environmental Science and Engineering: 293-297. Beijing.

Thorsell, J. 2003. A global overview of Mountain Protected Areas on the World Heritage List. Mountain Research and Development 23 (3): 290-291. Gland.

Wang, C. \& H. Xu 2014. The role of local government and the private sector in China's tourism: The issue of sustainability. Tourism Management 45: 95-105. Guangdong.

Wei, F. 2007. Analysis on the Relation of Chess Playing between the Habitants in Tourist Community and the Benefits Related People: Taking the natural set performance of landscape of Guilin "The Impression on Sister Liu" as an example. Study of Ethnics in Guangxi: 197-205. Nanjing.

Wimmer, A. 2009. Herder's Heritage and the Boundary-Making Approach: Studying Ethnicity in Immigrant Societies. Sociological Theory 27 (3): 244-270. Los Angeles.

Xie, G.D., S.Y. Cao, C.X. Lu, et al. 2010. Human's Consumption of Ecosystem Services and Ecological Debt in China. Journal of Natural Resources 25 (1): 4351. Beijing.

Xu, X.L., Z.P. Yang, A. Saiken et al. 2012. Natural Heritage value of Xinjiang Tianshan and global comparative analysis. Journal of Mountain Science 9 (2): 262 273. Urumqi.

Yang, Z.P., X.L. Zhang, Y.N. Liang, et al. Advisory Body Evaluation of Xinjiang Tianshan. Available at: http://whc.unesco.org/en/list/1414/documents / (accessed 20/02/2013).

Yang, M.Y., F. Van Coillie, L. Hens et al. 2014. Nature conservation versus scenic quality: A GIS approach towards optimized tourist tracks in a protected area of northwest Yunnan, China. Journal of Mountain Science 11 (1): 142-155. Kunming.

Yeh, E.T. 2003. Tibetan range wars: Spatial politics and authority on the grasslands of Amdo. Development and Change 34 (3): 499-523. Berkeley.
Zhang, A.M. \& Y.W. Li 2008. Analysis of the Exploration of New Scenic Spots Based on the Game Balance of Stakeholders-A Case Study of the Exploration of Qingshui River Scenic Spots in Pingdingshan City. Journal of Henan University. Natural Science 38 (2): 171-175. Kai feng.

Zhang, W.Y. 2004. Game theory and information economics. Shangha.

Zhang, C.Z. 2008. Tourism and heritage protection: based on the theory study of the case. Tianjin.

Zhao, H.F., Z.Y. Ouyang, H. Zheng et al. 2009. Valuation of glacier ecosystem services in the Manas River Watershed, Xinjiang. Acta Ecologica Sinica 29 (11): 5877-5881. Beijing.

Zhao, X.N. 2008. Interest game and "heritage" crisis: the theory of the improper development surrounding the world cultural heritage in our country. Journal of Southwest University for Nationalities 28 (12): 208-211. Chendu.

Zhou, K.F., X. Chen, H. Zhang et al. 2004. Study on the Model of Assessing the Ecological Service Value in Arid Areas. Arid Land Geography 27 (4): 492-497. Urumqi.

\section{Authors}

\section{Hui Shi}

Her research focuses on the protection and conservation of world natural heritage. University of Chinese Academy of Sciences, Beijing 100049, China. Xinjiang Institute of Ecology and Geography, CAS, Urumqi 830011, China. Email: shihui_129@163.com

\section{Zhaoping Yang - Corresponding author}

Professor of tourism geography. Her research focuses on tourism geography and the protection of world natural heritage. Xinjiang Institute of Ecology and Geography, CAS, Urumqi 830011, China.

Email: yangzhaoping_123@126.com

\section{Tiange Shi}

His research focuses on regional economy and urban geography. University of Chinese Academy of Sciences, Beijing 100049, China. Xinjiang Institute of Ecology and Geography, CAS, Urumqi 830011, China. Email: shitiangehust@126.com

\section{Fang Han}

Her research focuses on tourism geography and the protection of world natural heritage. Xinjiang Institute of Ecology and Geography, CAS, Urumqi 830011, China. Email: hanfang@ms.xjb.ac.cn 